\title{
Adsorption of Triterpene Extracts of Momordica charantia (Cucurbitaceae) Leaves by Local Kaolin from Boboyo, Far North Region (Cameroon)
}

\author{
Wangmene Bagamla ${ }^{1}$, Djakba Raphael ${ }^{1, ~ *, ~ H a r o u n a ~ M a s s a i ~}{ }^{2}$, Loura Benguellah Benoit ${ }^{3}$ \\ ${ }^{1}$ Department of Chemistry, Faculty of Science, University of Maroua, Maroua, Cameroon \\ ${ }^{2}$ Department of Chemistry, Chemical Engineering and Mineral Industries, University of Ngaoundéré, Ngaoundéré, Cameroon \\ ${ }^{3}$ Department of Textile and Leather Engineering, National Advanced School of Engineering of Maroua, Maroua, Cameroun
}

Email address:

djakbakon@gmail.com (D. Raphael),wangwe2012@yahoo.fr (D. Raphael)

${ }^{*}$ Corresponding author

\section{To cite this article:}

Wangmene Bagamla, Djakba Raphael, Harouna Massai, Loura Benguellah Benoit. Adsorption of Triterpene Extracts of Momordica charantia (Cucurbitaceae) Leaves by Local Kaolin from Boboyo, Far North Region (Cameroon). American Journal of Chemical and Biochemical Engineering. Vol. 5, No. 1, 2021, pp. 8-20. doi: 10.11648/j.ajcbe.20210501.12

Received: January 18, 2021; Accepted: January 26, 2021; Published: March 4, 2021

\begin{abstract}
Plant extracts are nowadays cited as suitable tools for better protection of stored grains insect pest attacks. These chemical insecticides are less attractive to producers because of their low persistence and difficulty to use as pure product. The present work aimed to study the formulation through adsorption of tetracyclic triterpene of the leaves of Momordica charantia (Cucurbitaceae) on kaolin. tetracyclic triterpene was obtained by macerated in methanol solvent. In this study, we tested the technical properties of kaolin physically and chemically, which include XRF, XRD, and FTIR. Based on the XRF test, the main composition of kaolin, $\mathrm{SiO}_{2}, \mathrm{Al}_{2} \mathrm{O}_{3}$, and $\mathrm{Fe}_{2} \mathrm{O}_{3}, \mathrm{CaO}, \mathrm{MgO}, \mathrm{K}_{2} \mathrm{O}, \mathrm{Na}_{2} \mathrm{O}, \mathrm{SO}_{3}, \mathrm{P}_{2} \mathrm{O}_{5}$ were 45.41, 20.54, 8.10, 0.13, 0.79, 01.10, $01.09,0.04$, and $0.03 \%$ respectively, while the rest were impurities. The FTIR spectra showed the functional groups of Al-OH, $\mathrm{Al}-\mathrm{O}$ and Si-O. While the XRD diffractogram identified kaolinite as the main mineral phase in the presence of quartz, muscovite, and grossite tested in small quantities in the sample. The experimental parameters such as contact time, adsorbent dose, initial concentration of extract of triterpene and temperature were studied. The study revealed that the maximum quantity of adsorption is reached after 10 minutes, it is believed that the quantities adsorbed with the increase in the concentration of the adsorbate and quantities adsorbed decreases with the increase of the mass of the clay and temperature. The adsorbent showed good potential for adsorption with a maximum take up of $0.34 \mathrm{mg} / \mathrm{g}$. The equilibrium data were well fitted by the Langmuir isotherm. Thermodynamic parameters suggested that the adsorption involved a chemical process, spontaneous, and endothermic in nature. The kinetic study showed that the second-order model gives a better description of the kinetics of the adsorption reaction. The study of the adsorption of triterpene extract by kaolinite can be used for a powdery formulation of insecticide.
\end{abstract}

Keywords: Isotherm Model, Kinetic Model, Tetracyclic Triterpene, Kaolinite, Thermodynamic Parameters

\section{Introduction}

Plant extracts are compounds concentrated in molecules derived from plant metabolism. The secondary metabolites originating from the latter have very important functions for the survival and proliferation of the plants such as chemical signals, defense producer against herbivores and pathogens as they participate in allelopathic responses (competition between plants for germination and growth) [1,2]. Some provide protection against solar radiation and others facilitate the dispersal of pollen and seeds [3]. They are produced in very small quantities, of which more than 200,000 molecules have been identified such as phenolic compounds, alkaloids and terpenoids [2, 3]. The dynamics market of the constituents of these extracts is supported by an everincreasing demand for natural ingredients. Thus, they are widely exploited by humans in the various fields, namely culinary as colors and flavors, medicinal as antibiotics, 
antioxidant, drugs and agricultural as insecticides [4]. Momordica charantia is one of those popularly known plants for its numerous medicinal virtues. This plant belongs to the Cucurbitaceae family. It grows in tropical areas of the Amazon, Africa, Asia, India, South America, and the Caribbean and is used traditionally as both food and medicine $[5,6]$. The plant is beneficial for its anti-tumorous, anti-fungal, anti-parasitic, anti-cancer, antiviral, anti-fertility, anti-bacterial and hypoglycaemic properties due to the presence of numerous phytochemicals [7]. In traditional medication, its fruits and leaves are used to cure several diseases like: gout, rheumatism, colic, worms, liver diseases and spleen [7]. These biological activities are attributed to their complex chemical composition; they are rich in proteins, triterpens, saponins, flavonoids, steroids, alkaloids, and acids [8]. The bioactive compounds are commonly obtained through conventional extraction techniques with many different types of organic solvents [5]. However, the work of Adesina et al. [9], Obembe et al. [10], Shibu et al. [11] and Zijun et al. [12] carried out on Momordica charantia shows that the methanol extract of leaves of this plant have insecticidal properties. Among the various constituents identified on the polar fraction of the methanol extract of leaves, we can highlight as characteristic of $M$. charantia the momordicines I and II [13]. The structures of the momordicines I and II were elucidated as $3 \beta, 7 \beta, 23$ ] trihydroxycucurbita-5,24-dien-19-al and its 23-O- $\beta$ glucopyranoside, respectively [13]. Momordicines "cucurbitane-type triterpenoids" are the most important purified bioactive constituents isolated from the leaves of this plants which justify it insecticidal activitie $[12,14]$. Thus, the industrial use of these compounds poses many problems because of the variability of their composition, their instability in storage and the allergenic potential of some of their constituents. Currently, it is recognized that temperature, light and oxygen availability have a major impact on the preservation of the integrity of the extract [15]. Faced with this handicap, fixing these extracts of triterpene to the surface of a solid support is one of the most used techniques. The clay, material power adsorbing, can be used as a support for organic compounds [16]. Thus, triterpenes compounds of optimized extracts from $M$. charantia fixed on clay constitutes a possible approach for producing a powdery insecticide formulation for industrial purposes. It is in this perspective that we are committed to promoting the development of a powdery insecticide formulation on the basis of triterpenes compounds of optimized extracts from the leaves of $M$. charantia and natural clay of Boboyo in view to reduce the extract concentration introduced without affecting the effectiveness of the finished product as well as modulating its release by prolonging its kinetic profile.

\section{Material and Methods}

\subsection{Mineral Materials}

The kaolin was collected from Boboyo locality (Far
North Region of Cameroon) deposit. The samples taken were packaged in plastic paper packaging and transported to the laboratory. After collecting the raw clay lumps, stones and other heavy particles were removed from the samples mechanically. The samples taken were packaged in plastic paper packaging and transported to the laboratory. A $320 \mathrm{~g}$ of each sample was then dispersed in $16 \mathrm{~L}$ of distillated water for one week. The suspension was then used to obtain sample with size less than $2 \mu \mathrm{m}$ by using sedimentation operation based on stocks law in an adapted disposal material as described by Nguemtchouin et al. [17].

The clay sample previously extracted (to obtain particles less than $2 \mu \mathrm{m}$ size particles) was then made homoionic sodium, focusing to remove all the undesired cation contained in the material clay used by replacing all the exchangeable cations of the natural clay by $\mathrm{Na}^{+}$ ions. The method applied is the same used by Nguemtchouin et al. [17]. $50 \mathrm{~g}$ of clay sample are introduced into a beaker containing $2 \mathrm{~L}$ of a $1 \mathrm{M} \mathrm{NaCl}$ (99.8\% pure) solution. The mixture is stirred for $24 \mathrm{~h}$ with a magnetic stirrer. The sodium kaolin $\left(\mathrm{Na}^{+} \mathrm{Kaol}\right)$ was separated using centrifugation and washed in distilled water until no residual halogen anions were detected by adding a $0.1 \mathrm{~mol} \cdot \mathrm{L}^{-1}$ of silver nitrate $\left(\mathrm{AgNO}_{3}\right)$ solution to the filtrate. The suspension obtained was dried at $70^{\circ} \mathrm{C}$ for $24 \mathrm{~h}$ and the sodium clay obtained was sprayed into a porcelain mortar and sieved.

\subsection{Plant Material and Maceration Procedure}

The plant material consists of fresh leaves of $M$. charantia (Cucurbitaceae), locally called "Bitter melon". These leaves were harvested in Djarengol, in Maroua III Subdivision, Department of Diamaré, Far North Region (Cameroon) in November 2018 and identified by Dr Froumsia, Botanist at the University of Maroua. The plant material was then cut and dried in the laboratory for three weeks at $25^{\circ} \mathrm{C}$. Finally, the dry leaves were pulverized in a grinder to obtain a fine powder. It was ground in a mortar and macerated for 72 hours in $3 \mathrm{~L}$ of methanol $(99.9 \%$ pure), then filtered on Whatman $\mathrm{N}^{\circ} 1$ filter paper. The filtrate was concentrated in a BUCHI brand rotary evaporator at $75^{\circ} \mathrm{C}$ and dried in an oven at $50^{\circ} \mathrm{C}$.

\subsection{Optimization of the Triterpene Extract}

In order to optimize the extract of the triterpene compound, $20 \mathrm{~g}$ of the methanol extract $(\mathrm{MeOH})$ were taken up in 200 $\mathrm{mL}$ of distilled water [18]. The aqueous solution thus obtained underwent a liquid-liquid extraction with hexane (Hex). To do this, the aqueous solution obtained was brought into contact with $200 \mathrm{~mL}$ of hexane and the whole underwent mechanical stirring for 30 minutes. After decantation, the two portions of each organic phase were combined and dried in an oven $\left(50^{\circ} \mathrm{C}\right)$. At the end of this evaporation, the obtained hexanic extract was kept in the tightly closed bottle with aluminum foil under a lid. 


\subsection{Chemical Structure of the Bioactive Compounds in the Extract}

Momordicin I and II were isolated and purified from M. charantia leaves using previously described methods by Popovich et al. [19]. Momordicin I and II purity was determined by high performance liquid chromatography (HPLC) and final purity was $97 \%$ for both compounds (Figure 1). Momordicin I and II were variably hydrophobic requiring dissolution in DMSO prior to dilution to final treatment concentrations. DMSO was used as a control vehicle in this experiment and adjusted to a final concentration of $0.5 \%$ in culture medium.
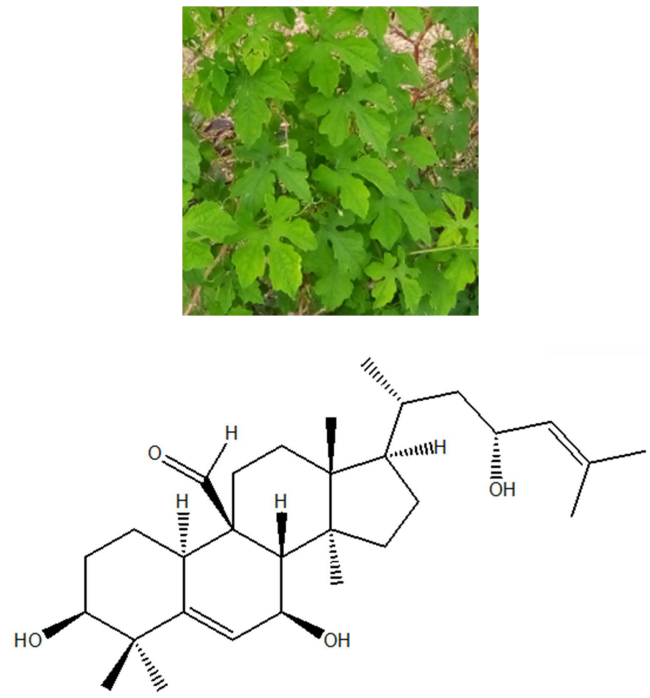

\section{Momordicin I}

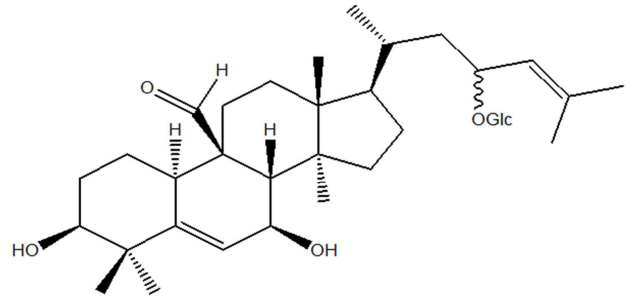

Momordicin II

Figure 1. Chemical structure of Momordicin I and II [12].

\subsection{Determination of Lupeol}

The reference compound used in this work is lupeol, a pentacyclic triterpene isolated from the ethyl acetate extract of the leaves of prosopis africana in the ratio hexane/ethyl acetate (95: 5). The demonstration of this compound was carried out by the reagent of Liberman Buchard. Therefore, to $5 \mathrm{~mL}$ each of these dilute solutions, $5 \mathrm{~mL}$ of the acetic anhydrous / chloroform mixture (5/5: V/V) are added; then filter and treat the filtrate with a few drops of concentrated sulfuric acid until a green-purple color appears [20, 21]. Their absorbances are measured by UV-Visible spectrophotometry at $530 \mathrm{~nm}$ against the blank consisting of the supernatant obtained from a suspension of clay in methanol.

\subsection{Adsorption of Triterpene Extracts by Clay}

The adsorption experiments were carried out using the batch equilibration technique. The solutions of the triterpene extracts of 20,40,60, 80 and $100 \mathrm{mg} / \mathrm{L}$ concentrations are introduced in the flasks in pyrex of $100 \mathrm{~mL}$. A mass determined of pillared clay is introduced in each solution. The suspensions were mixed on a rotary tumbler for 15 minutes. After phase separation by centrifugation the concentration of triterpene extracts. The filtrate (liquid phase) is then recovered and assayed by Liberman Buchard's reagent to be analyzed by UV-visible spectroscopy at wavelength of $530 \mathrm{~nm}$ and the solid phase, the clay complextriterpene extracts which is most often an adsorption waste however constitutes the desired product. The samples were pipetted from the solution colored by the aid of a very thin point micropipette, which prevented the transition to the solution of the clays samples. The amount of dye adsorbed was calculated using the equation [22]:

$$
q_{e}=\frac{\left(C_{0}-C_{e}\right) V}{m}
$$

Where $\mathrm{q}_{\mathrm{e}}$ is the equilibrium adsorption capacity per gram dry weight of the adsorbent $(\mathrm{mg} / \mathrm{g}), \mathrm{C}_{0}$ is the initial concentration of triterpene extracts in the solution $(\mathrm{mg} / \mathrm{L}), \mathrm{Ce}$ is the final or equilibrium concentration of triterpene extracts in the solution $(\mathrm{mg} / \mathrm{L}), \mathrm{V}$ is the volume of the solution $(\mathrm{L})$, and $\mathrm{m}$ the adsorbent mass $(\mathrm{g})$.

Determination of specific surface area

Saers'method was used for the determination of the surface area [23, 24]. By agitating $1.5 \mathrm{~g}$ of the adsorbent sample for each in $100 \mathrm{ml}$ of diluted hydrochloric acid of $\mathrm{pH}=3$. Then $30 \mathrm{~g}$ of Sodium Chloride was added with stirring and the volume was made up of $150 \mathrm{ml}$ with deionized water. The solution was titrated with $0.1 \mathrm{M} \mathrm{NaOH}$ and the volume, $\mathrm{v}$ needed to raise the $\mathrm{pH}$ from 4-9 was then recorded. The surface area according to this method was calculated using the following equation.

$$
\mathrm{S}\left(\mathrm{m}^{2} / \mathrm{g}\right)=32 \mathrm{~V}-25
$$

\section{Results and Discussion}

\subsection{Characteristics of Adsorbent}

\subsubsection{Fourier Transforms Infrared Analysis (FT-IR)}

In the FTIR spectra of kaolinite, the wide absorption band at $3695 \mathrm{~cm}^{-1}$, and $3622 \mathrm{~cm}^{-1}$ corresponds to the inner and outer structural hydroxyl Al-OH stretching with medium strength respectively. The peaks at $1634 \mathrm{~cm}^{-1}$, were the $\mathrm{H}-\mathrm{O}-$ $\mathrm{H}$ stretching and bending vibrations of the adsorbed water, respectively. In the region of low wavenumbers, there are characteristic bands of this clay at $991 \mathrm{~cm}^{-1}$ (Si-O stretching modes), $910 \mathrm{~cm}^{-1}$ (Al-Al-OH bonds) and $795 \mathrm{~cm}^{-1}$ (free silica and/or quartz admixtures, always present in natural samples). The peaks at $521 \mathrm{~cm}^{-1}$ and $454 \mathrm{~cm}^{-1}$ were assigned to the Si$\mathrm{O}-\mathrm{Al}$ and Si-O-Si bending vibration, respectively and 433 
$\mathrm{cm}^{-1}(\mathrm{Si}-\mathrm{O})$.

Table 1. Attribution of FT-IR spectrum bands of kaolinite.

\begin{tabular}{lll}
\hline Wavenumber $\left(\mathbf{c m}^{-1}\right)$ & Vibration type & References \\
\hline 3695 & OH, mainly Al-OH-Al & {$[29,30]$} \\
3622 & OH of Al-Al-OH & {$[31]$} \\
1634 & OH of water or Si-O, Si-O-Al & {$[32]$} \\
991 & Si-O of orthosilicates & {$[33]$} \\
910 & Al-Al-OH bonds & {$[25,34]$} \\
796 & Si-O stretching vibration of & {$[22,30]$} \\
686 & quartz & {$[30]$} \\
521 & Si-O- out-of-plane bending & {$[30,32]$} \\
454 & Si-O-Al bending, Al octahedral & {$[31]$} \\
433 & Si-O-Si in-plane bending & {$[22,30]$} \\
\hline
\end{tabular}

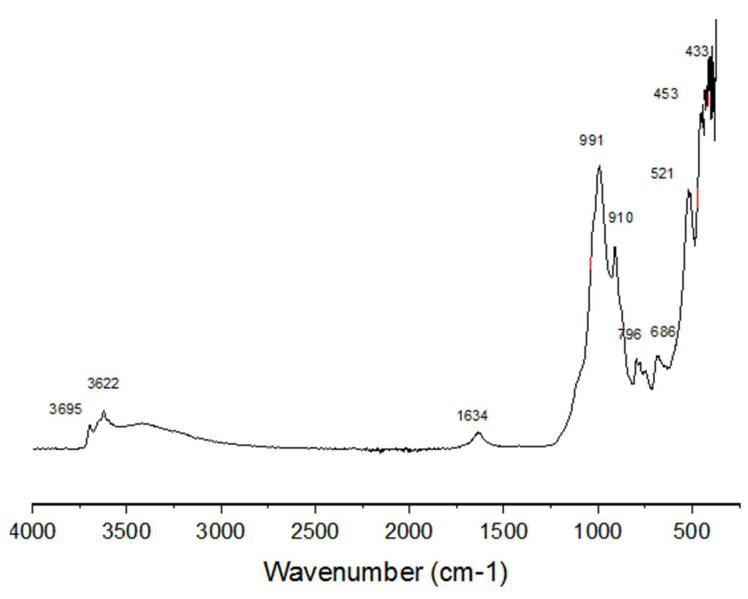

Figure 2. FT-IR spectrum of Boboyo clay.

The FTIR spectrum of triterpene of momordica. C extract was analyzed and depicted in Figure 3.

A wide absorption band at $3369 \mathrm{~cm}^{-1}$ was seen. Those bands were appointed to the vibration of the hydroxyl groups. A similar observation was reported by Supraja et al. [35]. The absorption peaks at 2924, $2855 \mathrm{~cm}^{-1}(=\mathrm{C}-\mathrm{H})$ and $1624 \mathrm{~cm}^{-1}$ $(\mathrm{C}=\mathrm{C})$ suggested that olefin was present in the compound and the band at $1708 \mathrm{~cm}^{-1}$ indicates the typical carbonyl group [35]. The FTIR spectrum region between 1200 and 1000 $\mathrm{cm}^{-1}$ was revealed that the $\mathrm{OH}$ side group's stretching vibration and the $\mathrm{CO}-\mathrm{C}$ glycosidic vibrations dominate the spectrum by overlapping the ring vibration [36].

The chemical bonds identified in the FTIR analysis demonstrated that the triterpenoid compounds present in momordica. $\mathrm{C}$ leaf extract.

FTIR-ATR analysis on the adsorption of triterpene extracts on kaolinite.

FTIR spectrum of kaolinite before and after adsorption was observed and displayed in Figure 4. After the adsorption of triterpene extracts, there was a substantial reduction in the intensity of the absorption peak in the range between 1200 $500 \mathrm{~cm}^{-1}$.

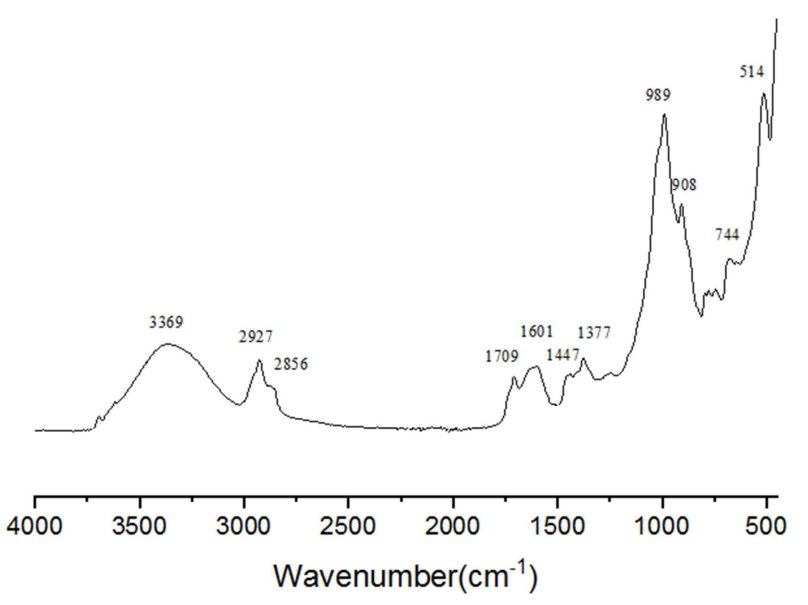

Figure 3. FT-IR spectrum of triterpene extracts from Momordica charantia leaves.

The intensity of the absorption band ranged between 1200$500 \mathrm{~cm}^{-1}$, which comprises of Si-O and Si-O-Si groups, inner surface $\mathrm{Al}-\mathrm{OH}$ groups, inner $\mathrm{Al}-\mathrm{OH}$ groups, and $\mathrm{Si}-\mathrm{O}-\mathrm{Al}$ and $\mathrm{OH}$ groups, was reduced, because of the interactions between those functional groups with triterpene extract. Similar results were obtained by [37].

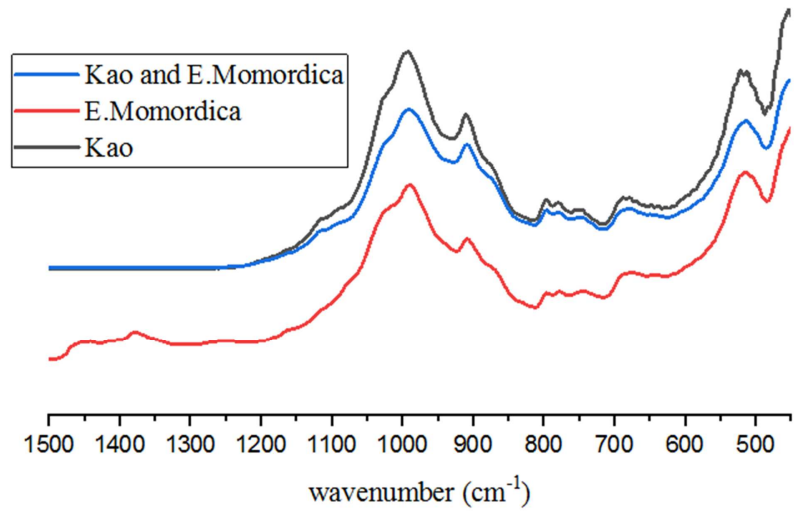

Figure 4. FT-IR analysis on the adsorption of triterpene extract on kaolinite.

\subsubsection{Elemental Composition of Adsorbent}

X-ray fluorescence (XRF) method has been used to identify the major minerals and chemical compounds present in the clays. The main oxides are $\mathrm{SiO}_{2}, \mathrm{Al}_{2} \mathrm{O}_{3}, \mathrm{Fe}_{2} \mathrm{O}_{3}, \mathrm{CaO}$, and $\mathrm{MgO}$. The kaolin was rich in $\mathrm{SiO}_{2}(45.41 \%)$, in $\mathrm{Fe}_{2} \mathrm{O}_{3}$ $(8.10 \%)$; and in $\mathrm{Al}_{2} \mathrm{O}_{3}(20.54 \%)$ and contained only small amounts of $\mathrm{CaO}, \mathrm{MgO}, \mathrm{K}_{2} \mathrm{O}, \mathrm{Na}_{2} \mathrm{O}, \mathrm{SO}_{3}$ and $\mathrm{P}_{2} \mathrm{O}_{5}$ (Table 2). Loss on ignition (LOI) was $15.26 \%$. The chemical composition indicated the presence of considerable amounts of silica-and iron-bearing impurities. According to reports by Shibu et al. [11], the kaolin has high amount of silica $69.30 \%$ and lower alumina $24.30 \%$. Other researchers achieved silica content of $47.81 \%$ and alumina $22.01 \%$; which is related to this report [38]. The specific surface area of the clay was determined using Saers' method, and the value obtained was $7.65 \mathrm{~m}^{2} \mathrm{~g}^{-1}$. 
Table 2. Elemental composition of Boboyo clay.

\begin{tabular}{lllllllllll}
\hline Compound & $\mathbf{S i O}_{2}$ & $\mathbf{A l}_{2} \mathbf{O}_{3}$ & $\mathbf{F e}_{2} \mathbf{O}_{3}$ & $\mathbf{C a O}$ & $\mathbf{M g O}$ & $\mathbf{K}_{2} \mathbf{O}$ & $\mathbf{N a}_{2} \mathbf{O}$ & $\mathbf{S O}_{3}$ & $\mathbf{P}_{2} \mathbf{O}_{5}$ & $\mathbf{L O I}$ \\
\hline $\mathrm{Wt}(\%)$ & 45.41 & 20.54 & 08.10 & 00.13 & 00.79 & 01.10 & 01.09 & 00.04 & 00.03 & 15.26 \\
\hline
\end{tabular}

\subsection{3. $X$ - ray Diffraction}

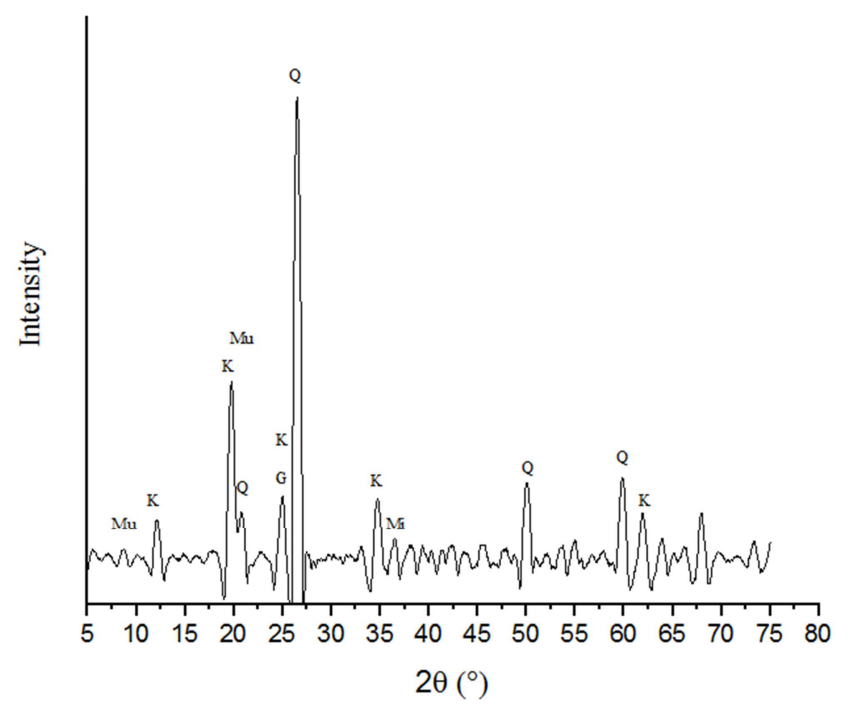

K: Kaolin; Q: Quartz; Mu: Muscovite; Mi: Microline; G: Grossite.

Figure 5. X-ray diffractogram of Boboyo clay.

The identification of the kaolin mineral component is done by comparing the peak intensity position $(2 \theta)$ in the sample $\mathrm{X}$-ray diffraction-gram with the peak position value of the diffraction intensity $(2 \theta)$ standards contained in the Joint Committee for Powder Diffraction Standards (JCPDS). The price of the peak intensity of the technical kaolin is shown in Figure 5. The absorption peaks appear at $2 \theta=12.26^{\circ} ; 20.77^{\circ}$; $20.97^{\circ} ; 25.19^{\circ} ; 26.53^{\circ} ; 34.9^{\circ} ; 35.8^{\circ}$ and others. These findings are consistent with other previously reported works [22]. The absorption peaks found at $2 \theta=12.26^{\circ} ; 20.77^{\circ}$; $20.97^{\circ} ; 25.19^{\circ} ; 26.53^{\circ} ; 34.9^{\circ} ; 35.8^{\circ}$. The peak at $2 \theta=12.26^{\circ}$ is the distinctive XRD form of kaolin $(\mathrm{K})$. Some impurities like quartz $(\mathrm{Q})$ (peaks around $20.97^{\circ} ; 26.53^{\circ}$ ), muscovite $(\mathrm{Mu})\left(8.15^{\circ} ; 20.77^{\circ}\right)$, microline $(\mathrm{Mi})\left(32.25^{\circ}\right)$ and grossite $(\mathrm{G})$ $\left(29.19^{\circ}\right)$ are also present. The kaolin sample showed predominant phases as kaolin and quartz, which are commonly found in kaolin as one of the major compositions.

\subsection{Adsorption Studies}

\subsubsection{Effect of Contact Time}

The study of the influence of time was carried out in order to determine the equilibrium time when the quantity of the triterpene extract fixed is maximum. The quantity adsorbed per gram of clay as a function of time is illustrated in Figure 6. The results presented have shown that the adsorbed amount of triterpene extract increases rapidly in the first 5 minutes to reach an optimum of $0.23 \mathrm{mg} / \mathrm{g}$ and remains approximately constant after 10 minutes, indicating a state of balanced. This shows that the balance of extract adsorption by the adsorbent used is very fast. The rapidity of the reaction is explained by the availability of the high number of vacant adsorption sites on the clay surface at the initial stage of adsorption. Then, adsorption gradually slows down as the remaining unoccupied outdoor sites are difficult to occupy. In addition, the extract molecules are medium in size and can be easily diffused into the internal pores until they are saturated, which will reduce mass transfer between the liquid phase and the solid phase over time. These lead to a decrease in the adsorption rate and we observe a plateau which corresponds to the state of equilibrium after 10 minutes. Consequently, maximum adsorption $(0.23 \mathrm{mg} / \mathrm{g})$ of triterpene extract is obtained after 10 minutes during our work. In the rest of this work, a contact time of $10 \mathrm{~min}$ seems largely sufficient to reach equilibrium.

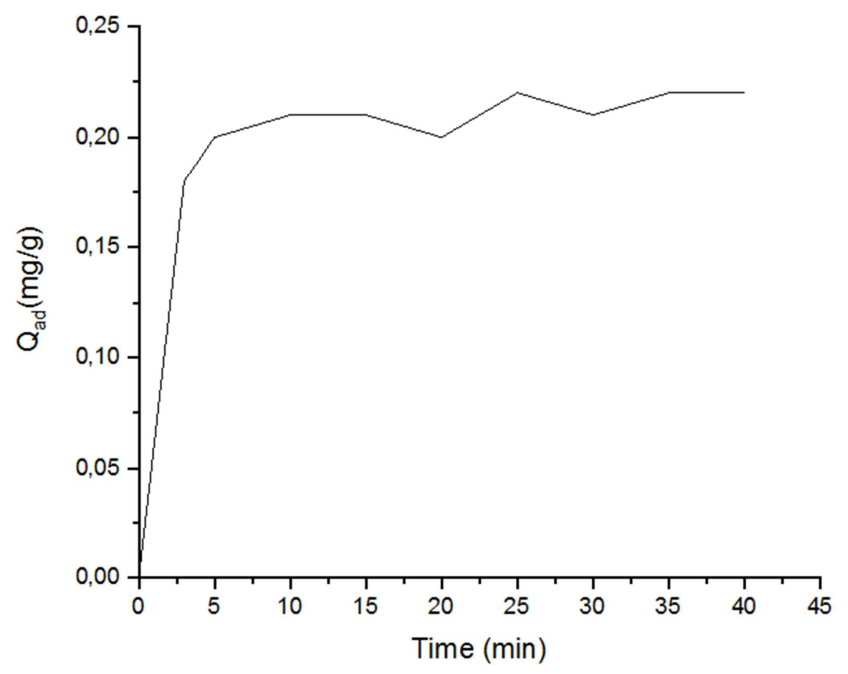

Figure 6. Effect contact time on adsorption of triterpene extract $\left(C_{0}=20 \mathrm{mg} / \mathrm{L} ; \mathrm{m}=0.02 \mathrm{~g} ; \mathrm{V}=20 \mathrm{~mL}, \mathrm{~T}=25^{\circ} \mathrm{C}\right)$.

\subsubsection{Effect of Solvent}

The study of influence of solvent on adsorption capacity of triterpene extract led us to vary methanol, hexane and ethyl acetate solvents while retaining the initial concentration of the substrate in solution and the initial mass of the adsorbent. Figure 7 gives us the variation of adsorbed quantities of these compounds according to the different solvents. Knowledge of the type of solvent used is an essential parameter for determining the maximum adsorption capacity in solution [39]. The results presented have shown that the variability of the organic solvent used has a remarkable influence on the adsorbed quantity of triterpene extracts. The amount of triterpene extract absorbed by the clay increases from ethyl acetate to methanol. Methanol was found to be the most suitable solvent for this adsorption study. This suggests that methanol has made it possible to make a strong interaction between the molecules of the extract and the different functional groups (Figure 3) present in the interfoliar spaces of the clay, implying the use of Van der Waals type bonds, 
hydrogen bonds and even can be chemical bonds [40]. Furthermore, the adsorbate used in our work was obtained by optimizing the methanol extract to triterpene using hexane as a solvent having a high affinity for this family of compound. However, the high adsorbed quantity observed in methanol compared to the other solvents could be explained by a greater solubility of the extract known as "optimized in triterpene" by the extraction solvent implying a strong interaction between clay and extract of triterpene [4, 41]. In contrast, the hexane extract believed to be the most concentrated in triterpene [18] was moderately fixed by clay. This could be explained by the process of polarization of the molecules of triterpene extract to the solvent used. Similarly, it has been reported by Sana et al. [4] and Jian et al. [42] that the solubilization of an organic compound does not necessarily depend on the type of solvent from which it was isolated but rather on the affinity of the compound to the solvent.

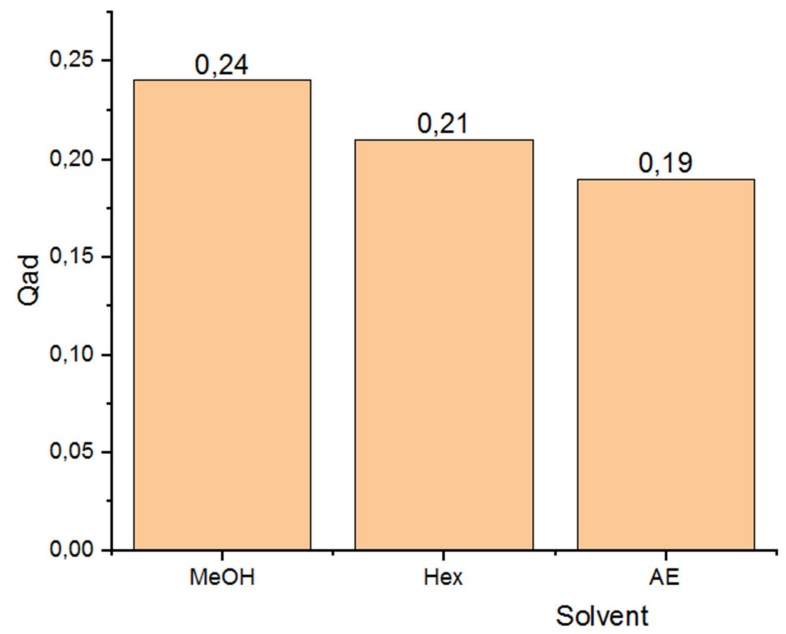

Figure 7. Effect of solvent on adsorption of triterpene extract (solvent: $A E$, $\mathrm{Hex}, \mathrm{MeOH} ; \mathrm{C}_{0}=20 \mathrm{mg} / \mathrm{L} ; \mathrm{m}=0.02 \mathrm{~g} ; \mathrm{V}=20 \mathrm{~mL}, t=30 \mathrm{~min}$ and $\mathrm{T}=25^{\circ} \mathrm{C}$ ).

\subsubsection{Effect of Dilution of Solvent}

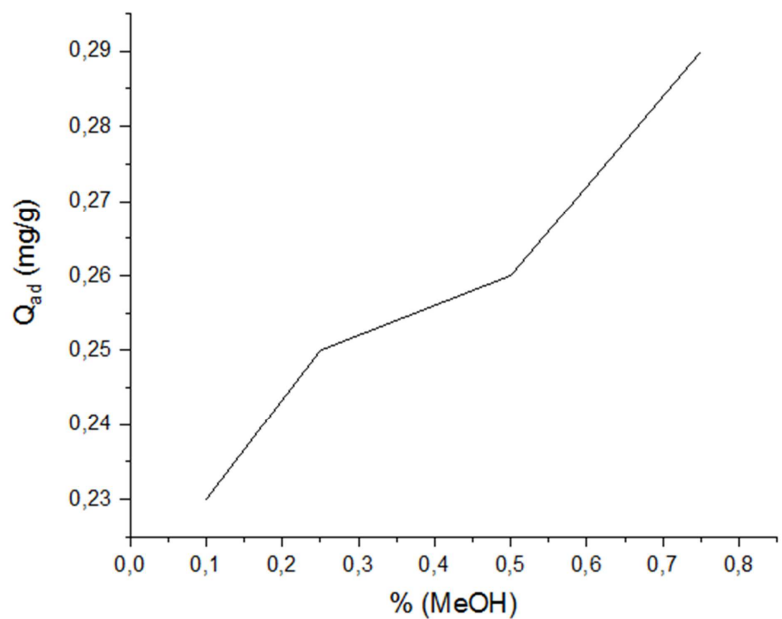

Figure 8. Effect of methanol dilution on adsorption of triterpene extract (MeOH10\%; $\mathrm{MeOH} 25 \%$; $\mathrm{MeOH} 50 \% ; \mathrm{MeOH} 75 \% ; C_{0}=20 m g / L ; m=0.02 \mathrm{~g}$; $V=20 \mathrm{~mL}$ and $T=25^{\circ} \mathrm{C}$ ).
The study of influence of dilution of solvent on adsorption capacity of triterpene extract has led us to vary the concentration of the methanol solvent from 10 to $75 \%$ while retaining the initial concentration of the substrate in solution. Figure 8 gives us the variation of the adsorbed quantity of this compound studied as a function of the concentration of the solvent.

The dilution of solvent is an important factor which can affect the adsorption process [43]. It appears from Figure 8 that, the increase in the amount of methanol in the medium results in an increase in the amount of triterpene extract adsorbed. The amounts adsorbed vary from 0.23 to $0.29 \mathrm{mg} / \mathrm{g}$ Indeed, the dilution of methanol caused the change from the most concentrated to the least concentrated medium tending towards the aqueous medium. Thus, the decrease in the adsorbed quantity observed could be influenced by the partial solubility of the adsorbate following the addition of a large amount of water in methanol. Consequently, a low dispersion of the molecules of the extract in the medium causes a decrease in the amount adsorbed. However, the increase in the adsorbed amount of triterpene extract in methanol could be justified easily by the phenomenon of the great solubilization of the extract by the solvent. Thus, the more the molecules are dispersed in the medium, the more they easily diffuse towards the adsorption sites.

\subsubsection{Effect of $\mathrm{pH}$}

The initial $\mathrm{pH}$ of dye solution is an important parameter which controls the adsorption capacity. This $\mathrm{pH}$ can be influenced by the surface charge of adsorbent, the degree of ionization of adsorbate molecule, and extent of dissociation of functional groups on the active sites of the adsorbent [44]. Hence, the adsorption of triterpene extract on the clay was examined from solution at different $\mathrm{pH}$ values covering a range of 3 to 11 . The highest adsorption capacity was obtained at $\mathrm{pH}=5$ while the maximum adsorption was 0.25 $\mathrm{mg} / \mathrm{g}$. The removal is affected by the change in the $\mathrm{pH}$ value of the solution. In acidic medium, the surface of the kaolinite is surrounded by $\mathrm{H}^{+}$ions, which decrease the interaction of the solute ions with the sites of the kaolinite material. On the contrary, in the basic medium, the concentration of $\mathrm{H}^{+}$ions decreases and generates a good interaction between the triterpene extract ions and the sites of the surface. The carbonyl and hydroxyl groups that present in the triterpene extract (momordicine) which contain electronegative oxygen were the groups that responsible for the electrostatic interactions between triterpene extract and the kaolinite. Similar adsorption behaviors of phenol were reported by several investigations [45]. In order to confirm this result, it was necessary to determine the $\mathrm{pH}_{\mathrm{pzc}}$ of the adsorbent. Therefore, the point of zero charge ( $\mathrm{pHpzc}$ ) of the adsorbent is the main parameter influencing the adsorption phenomenon. Generally, the zero point of charge of kaolinite is in order to $\mathrm{pH}=4.0$ [5]. When the solution has $\mathrm{pH}>\mathrm{pH}_{\mathrm{pzc}}$ the surface of the clay is negatively charged which promotes the adsorption of molecule cationic. For $\mathrm{pH}<\mathrm{pH}_{\mathrm{pzc}}$ the surface of the clay is 
charged positively, and thus likely to be repulsive to the molecule cations. The removal increase can be explained by electrostatic attraction between the particles of the material, which is positively charged, and the anionic molecule, which is negatively charged. Therefore, with increasing $\mathrm{pH}$ above $\mathrm{pH}_{\mathrm{pzc}}=4$, the removal of cationic molecule by the kaolinite increased slightly.

\subsubsection{Effect of Adsorbent}

The study of influence of mass of adsorbent applied on adsorption capacity of triterpene extract led us to vary the amount of the adsorbent from 0.02 to $0.1 \mathrm{~g}$ while retaining the initial concentration of the substrate in solution. It appears from Figure 10 that, the increase in the amount of adsorbent results in a decrease in the amount of triterpene extract adsorbed per unit of mass. The amounts adsorbed decrease from 0.22 to $0.04 \mathrm{mg} / \mathrm{g}$ with the increase in the mass of adsorbent. This can be explained by the fact that since the mass of adsorbent increases, there is a decrease in the number of active adsorption sites due to the superposition of the particles of adsorbent on the surface of the solid and inversely the adsorbed amount of the triterpene extract causes the increase in the mass of adsorbent. This result could also be justified by the phenomenon of normalization of the quantities adsorbed. Indeed, the increase in the amount of adsorbent leads to an increase in its total available surface area without any influence on the content of triterpene extract in the medium. This may be due to the creation of an aggregation of particles and a slowdown in the diffusion of molecules in the pores of the material [47]. Thus, the less saturated the medium, the more easily the molecules diffuse towards the adsorption sites. This evolution is in accordance with the kinetic stages of liquid phase adsorption which are external diffusion (transfer of the solute to the surface of the solid of the adsorbent), diffusion on the surface of the solid, intraparticle diffusion (diffusion in the pore) and the adsorbent-adsorbate interaction. Thus, in the rest of our work, an amount of $0.02 \mathrm{~g}$ of clay will be necessary to fix the maximum amount of triterpene extract.

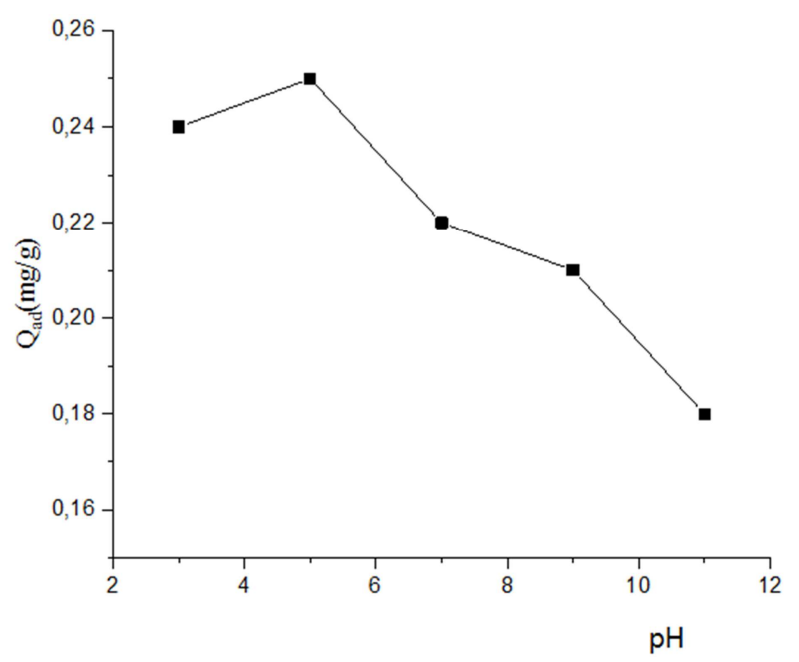

Figure 9. Effect of $p H$ on adsorption of triterpene extract (solvent: $10 \% \mathrm{MeOH} ; \mathrm{C}_{0}=20 \mathrm{mg} / \mathrm{L} ; \mathrm{m}=0.02 \mathrm{~g} ; \mathrm{V}=20 \mathrm{~mL}, t=10 \mathrm{~min}$ and $\mathrm{T}=25^{\circ} \mathrm{C}$ ).

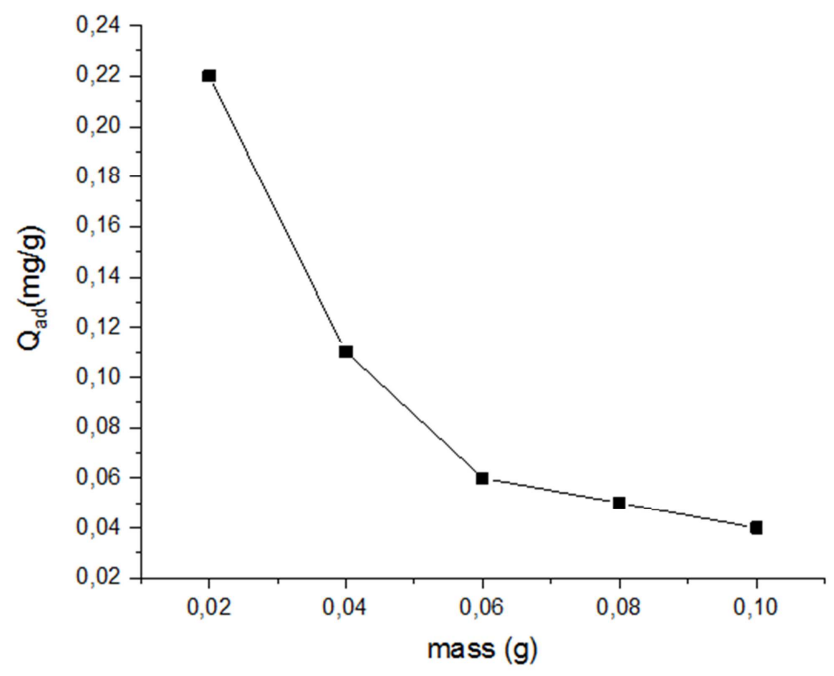

Figure 10. Effect of adsorbent dosage on adsorption of triterpene extract (MeOH75\%; $C_{0}=20 \mathrm{mg} / \mathrm{L} ; \mathrm{m}=0.02 \mathrm{~g} ; \mathrm{m}=0.04 \mathrm{~g} ; \mathrm{m}=0.06 \mathrm{~g} ; \mathrm{m}=0.08 \mathrm{~g}$; $m=0.1 \mathrm{~g} ; \mathrm{T}=25^{\circ} \mathrm{C}$ ).

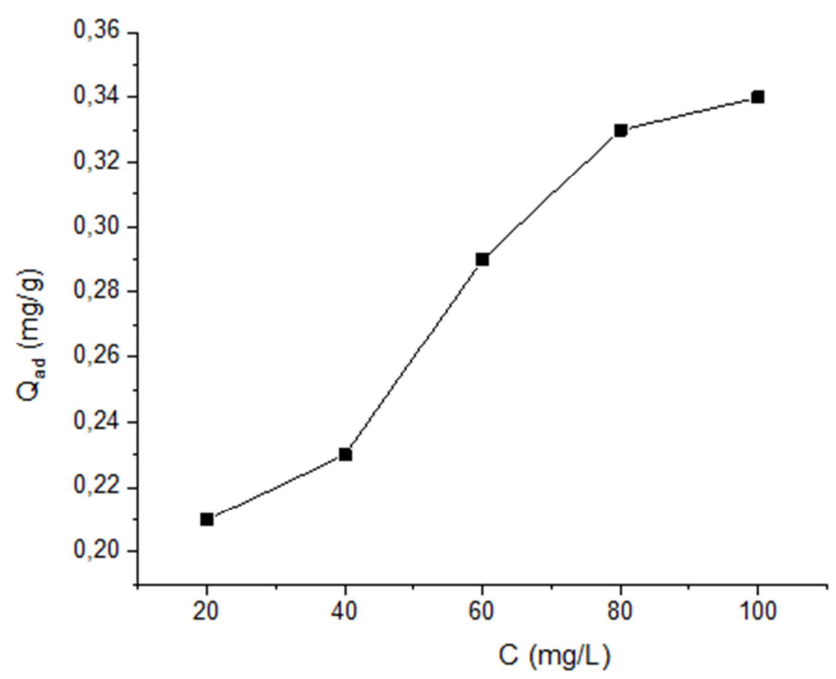

Figure 11. Effect of concentration on adsorption of triterpene extract (solvent: $\mathrm{MeOH} 75 \%$; $C=20 \mathrm{mg} / \mathrm{L} ; C=40 \mathrm{mg} / \mathrm{L} ; C=60 \mathrm{mg} / \mathrm{L} ; C=80 \mathrm{mg} / \mathrm{L}$; $C=100 \mathrm{mg} / \mathrm{L} ; \mathrm{m}=0.02 \mathrm{~g} ; \mathrm{V}=20 \mathrm{~mL}, T=25^{\circ} \mathrm{C}$ ).

\subsubsection{Effect of Initial Concentration of Triterpene Extract}

The influence of initial concentration of triterpene extract on the adsorption capacity of the clay was carried out with a mass of the material of $0.02 \mathrm{~g}$, a contact time of $10 \mathrm{~min}$ and at a temperature of $25^{\circ} \mathrm{C}$. The results obtained are shown in Figure 11. It can be seen from Figure 11 that the adsorbed amount of triterpene extract increases considerably with the increase in the concentration of adsorbate. The increase in the concentration causes the increase in the training force of the concentration gradient therefore the increase in the molecular diffusion of triterpene in solution on the surface of the adsorbent. The percentage of the maximum amount adsorbed for an initial concentration of $100 \mathrm{mg} / \mathrm{L}$ is around $1.75 \%$. The result seems to indicate that if the concentration of the molecules is high in the solution, there will therefore be more molecules which will diffuse towards the surface of the sites of the particles of the support and consequently the retention 
becomes more important. Thus, the higher the concentration of the solution, the more numerous the molecules of extract in the solution and the more they are in contact with the adsorbent then the percentage of adsorption increases [48, 49]. Similarly, the increase in the initial concentration of triterpene extract would result in an increase in the number of molecules present in the medium and therefore in the number of molecules adsorbed per unit mass of clay. This phenomenon was also observed in 2016 by [28]. who, working on the adsorption of gallic acid and the optimized extract of the bark of the pittosporum viridiflorum (pittosporaceae) trunk by Boboyo clay, found a maximum percentage of elimination of $11.82 \mathrm{mg} / \mathrm{g}$ with a concentration compared to the results of the present work.

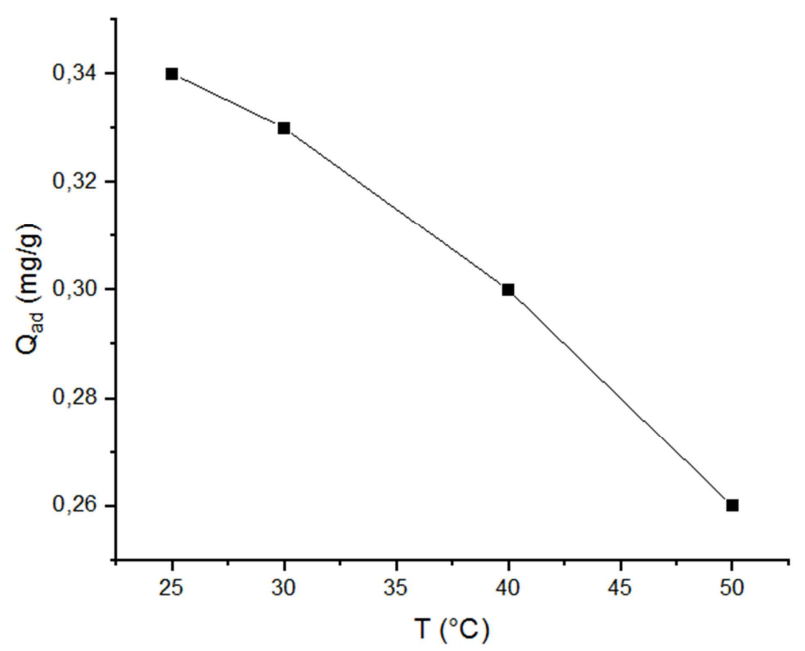

Figure 12. Effect of temperature on adsorption of triterpene extract $\left(T=25^{\circ} \mathrm{C}, \mathrm{T}=30^{\circ} \mathrm{C} ; \mathrm{T}=40^{\circ} \mathrm{C} ; \mathrm{T}=50^{\circ} \mathrm{C} ; \mathrm{Co}=100 \mathrm{mg} / \mathrm{L} ; \mathrm{m}=0.02 \mathrm{~g} ; \mathrm{V}=20 \mathrm{~mL}\right)$.

\subsubsection{Effect of Temperature}

Temperature is a major variable in the adsorption process. It is found that the quantity adsorbed decreases when the temperature increases. Figure 12 shows the variation in the amount of triterpene extract adsorbed as a function of temperature. Temperature is an important factor that can affect the adsorption process. From this result, there is a gradual decrease in the amount of triterpene extract adsorbed per gram of clay from 0.34 to $0.26 \mathrm{mg} / \mathrm{g}$ when the temperature increases from 25 to $50^{\circ} \mathrm{C}$. Indeed, the decrease in the adsorption capacity with the increase in temperature would be due on the one hand to the degradation of triterpene extract previously fixed to the surface of the clay material [42] and on the other hand by the destruction of the functional groups present on the surface of the adsorbent as shown in Figure 2 above. Similarly, this decrease would also be due to the weakening of the adsorptive forces between the active sites on the adsorbent and the molecules of triterpene extract following the increase in temperature [28]. Similarly, the decrease in the efficiency of adsorption at high temperatures has also been explained by the fact that several particles of clay adsorbents are destroyed at temperatures above $25^{\circ} \mathrm{C}$ and the suspension (Clay+solution) becomes homogeneous at elevated temperatures [28]. These results are contrary to those obtained by Aksas [49] and Domga [50]. Overheating adversely affects the course of the adsorption phenomenon and can lead to an increase in the desorption kinetics. Thus, the decrease in the adsorption capacity with temperature indicates that the process is exothermic and would lead under these conditions to physical adsorption. So the best results are obtained in the area of ambient temperature.

A study of the temperature dependence of the adsorption process gives valuable information about thermodynamic aspect of the adsorption. The thermodynamic parameters for the present study including Gibbs free energy of adsorption $\Delta \mathrm{G}^{\circ}$, changes in enthalpy of adsorption $\left(\Delta \mathrm{H}^{\circ}\right)$ and changes in entropy of adsorption $\left(\Delta \mathrm{S}^{\circ}\right)$, were determined using the following equations [51]:

$$
\begin{gathered}
\Delta \mathrm{G}=-R T \ln K c \\
\ln K c=\frac{\Delta S^{\circ}}{R}-\frac{\Delta \mathrm{H}^{\circ}}{R T} \\
\Delta \mathrm{G}^{\circ}=\Delta \mathrm{H}^{\circ}-T \Delta \mathrm{S}^{\circ}
\end{gathered}
$$

Where $\mathrm{R}$ is the universal gas constant $(8.314 \mathrm{~J} / \mathrm{mol} . \mathrm{K})$ and $\mathrm{T}$ is the solution temperature in $\mathrm{K}$.

The equilibrium constant $(\mathrm{Kc})$ can be calculated using the equation below:

$$
\mathrm{Kc}=\frac{\mathrm{Qe}}{\mathrm{Ce}}
$$

Equilibrium constant $(\mathrm{Kc})$ for the adsorption process was determined by plotting $\ln \mathrm{q}_{\mathrm{e}} / \mathrm{Ce}$ vs $\mathrm{q}_{\mathrm{e}}$ and extrapolating to zero $\mathrm{q}_{\mathrm{e}}$. The values of $\Delta \mathrm{H}^{\circ}$ and $\Delta \mathrm{S}^{\circ}$ were obtained from the slope and the intersection with the intercept at the origin of $\ln$ (Kc) versus 1/T (Figure 10).

Table 3. Thermodynamic parameters relative of adsorption of triterpene extracts on clay mineral at different temperatures.

\begin{tabular}{lllll}
\hline $\mathbf{T}(\mathbf{K})$ & $\Delta \mathbf{G}(\mathbf{K J} / \mathbf{m o l})$ & $\mathbf{\Delta H}(\mathbf{K J} / \mathbf{m o l})$ & $\Delta \mathbf{S}(\mathbf{J} / \mathbf{m o l})$ & $\mathbf{R}^{\mathbf{2}}$ \\
\hline 298 & -11.121 & & & \\
303 & -11.208 & 99 & 37.32 & 0.770 \\
313 & -11.581 & & & \\
323 & -11.954 & & & \\
\hline
\end{tabular}

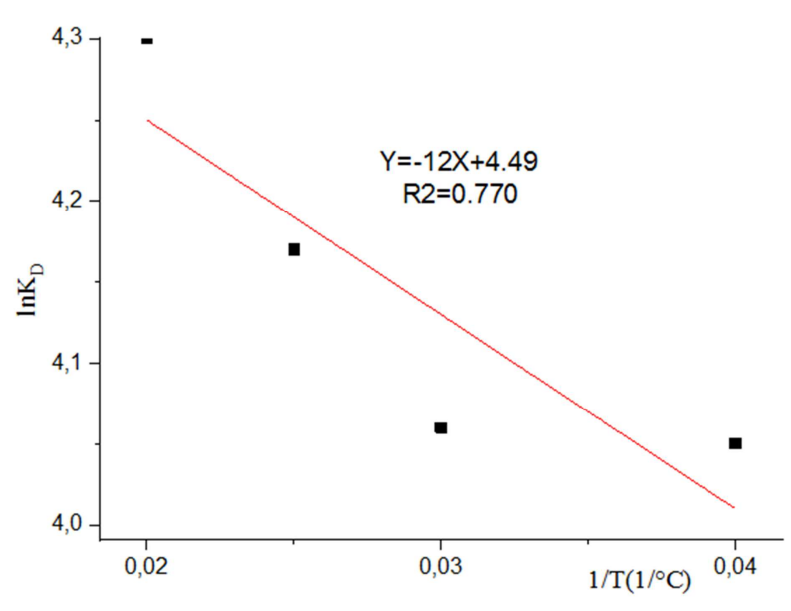

Figure 13. Plot of $\ln \left(K_{D}\right)$ versus temperature (1/T) for the adsorption of triterpene extracts on the clay. 
The thermodynamic parameters, the standard Gibbs energy $\left(\Delta G^{\circ}\right)$, standard enthalpy $\left(\Delta H^{\circ}\right)$ and entropy $\left(\Delta S^{\circ}\right)$ for triterpene extracts at various temperatures obtained are given in Table 3. It can be seen from this table that all the $\left(\Delta \mathrm{G}^{\circ}\right)$ values are negative, which indicates that the adsorption is spontaneous and thermodynamically favorable. However, the negative value DG decreased with an increase in temperature, indicating spontaneity of the adsorption process of the clay which was more favorable at higher temperatures. Similar observation is made in the adsorption of oxytetracycline on kaolinite [51]. Furthermore, the positive sign of $\Delta \mathrm{H}^{\circ}$ confirmed the endothermic nature of adsorption process. The value of $99 \mathrm{~kJ} / \mathrm{mol}$ for $\Delta \mathrm{H}^{\circ}$ higher than $40 \mathrm{~kJ} / \mathrm{mol}$ is indicative of chemical adsorption process occurring on the surface of clay material [52]. Besides, the positive values of the $\Delta \mathrm{S}^{\circ}$ show the increased randomness at the solid/liquid interface, with some structural changes in the adsorbate and adsorbent. Similar observation is made in the adsorption of oxytetracycline on kaolinite [52]. Increase in entropy for adsorption in the liquid phase has been reported by Adarsh et al. [53]. Normally, adsorption of gases leads to a decrease in entropy due to the orderly arrangement of the gas molecules on a solid surface. However, adsorption of solute from the solution on a solid surface is a complex phenomenon and the entropy of the system is determined by degree of freedom of adsorbate (solute) and solvent molecules. The positive value of entropy could be due to the affinity of the clay and desorption of solvent molecules from the surface of adsorbents.

\subsection{Isotherm Studies}

Adsorption properties and equilibrium parameters, commonly known as adsorption isotherms, describe how the adsorbate interacts with adsorbents, and comprehensive understanding of the nature of interaction. Isotherms help to provide information about the optimum use of adsorbents [22, 44]. When optimizing the design of an adsorption system, it is essential to establish the most appropriate correlation for the equilibrium curve. Several isotherm equations are available for analysis of experimental sorption equilibrium parameters. However, Langmuir and Freundlich models are the most widely used type of isotherm. These models were used to explain the interaction between triterpene extracts and kaolinite in this study. They are the best models for explaining adsorption trends and are based on the rationale that the adsorbents become saturated with adsorbate after sufficiently long contact times [22].

\subsubsection{Langmuir Isotherm}

The Langmuir model is suited to describe the adsorption of monolayer onto homogeneous surfaces. The adsorption can be represented by the following equation:

$$
\frac{C e}{q e}=\frac{1}{K L q \max }+\frac{\mathrm{Ce}}{\mathrm{qmax}}
$$

Where qe $(\mathrm{mg} / \mathrm{g})$ is the amount of dye adsorbed at equilibrium, $\mathrm{Ce}(\mathrm{mg} / \mathrm{l})$ is the equilibrium concentration, $\mathrm{KL}$ $(1 / \mathrm{g})$ is the Langmuir constant and $\mathrm{q}_{\max }$ is the monolayer adsorption capacity. In addition, one can use the Langmuir isotherm to extract a dimensionless term RL called the separation factor. The value of RL indicates the type of the isotherm (i) unfavorable ( $R L>1)$, (ii) linear $(\mathrm{RL}=1)$, (iii) favorable $(0<R L<1)$, or (iv) irreversible $(R L=0)$. It is defined as [44]:

$$
\mathrm{RL}=\frac{1}{1+K L C o}
$$

Where $\mathrm{KL}$ is the Langmuir constant and $\mathrm{C}_{0}$ is the initial concentration of adsorbate in solution.

\subsubsection{Freundlich Isotherm}

The Freundlich model is based on the fact that the adsorption takes place on heterogeneous surfaces and assumes that the absorption occurs on sites with different adsorption energies. The model gives a representation of the equilibrium between the amount of adsorbate in solution and that on the surface of the adsorbent. This equation is also applicable to multilayer adsorption and is expressed by the following equation:

$$
\log q e=\log K F+\frac{1}{n} \log C e
$$

Where qe is the amount of solute adsorbed per unit mass of adsorbent $(\mathrm{mg} / \mathrm{g}), \mathrm{Ce}$ is the equilibrium concentration, $\mathrm{KF}$ is the Freundlich constant and $\mathrm{n}$ is the heterogeneity factor. The value KF is related to the adsorption capacity, while the value of $(1 / n)$ is related to the adsorption intensity. When $n=1$, the adsorption is linear, meaning that sites are homogeneous and there is no interaction between the adsorbed species; when $1 / \mathrm{n}<1$, adsorption is favorable and the adsorption capacity increases while new adsorption sites appear. When $1 / \mathrm{n}>1$ adsorption is not favorable, adsorption bonds become weak and the adsorption capacity decreases.

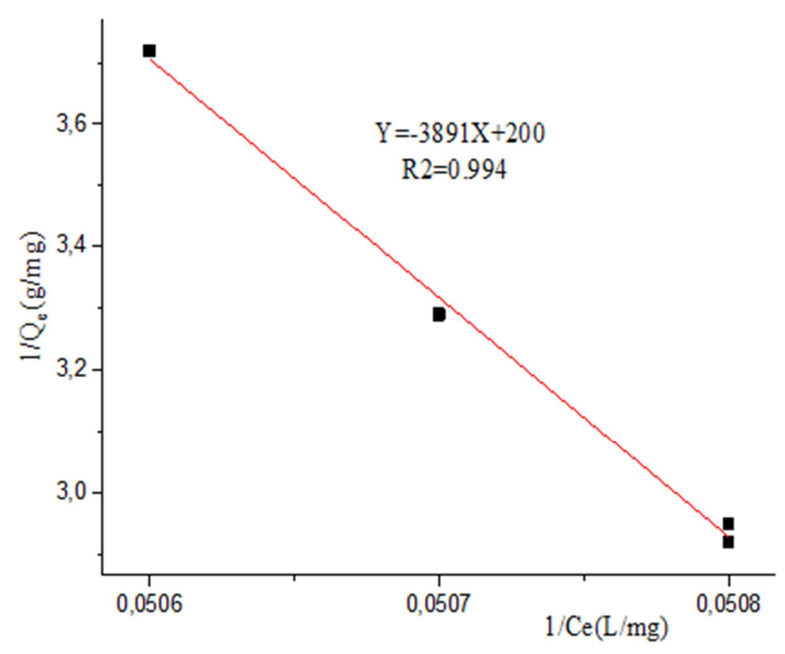

Figure 14. Linear plot of the model of Langmuir. 
Table 4. Langmuir and Freundlich isotherms constants.

\begin{tabular}{lllllll}
\hline Langmuir & \multicolumn{7}{c}{ Freundlich } \\
\hline $\mathbf{Q}_{\max }(\mathbf{m g} / \mathbf{g})$ & $\mathbf{K}_{\mathbf{L}}(\mathbf{L} / \mathbf{m g})$ & $\mathbf{R L}$ & $\mathbf{R}^{\mathbf{2}}$ & $\mathbf{K}_{\mathbf{F}}(\mathbf{m g} / \mathbf{g})$ & $\mathbf{1} / \mathbf{n}_{\mathbf{F}}$ & $\mathbf{R}^{\mathbf{2}}$ \\
\hline 0.0002 & 19.45 & 0.002 & 0.994 & 138.63 & 0.05 & 0.808 \\
\hline
\end{tabular}

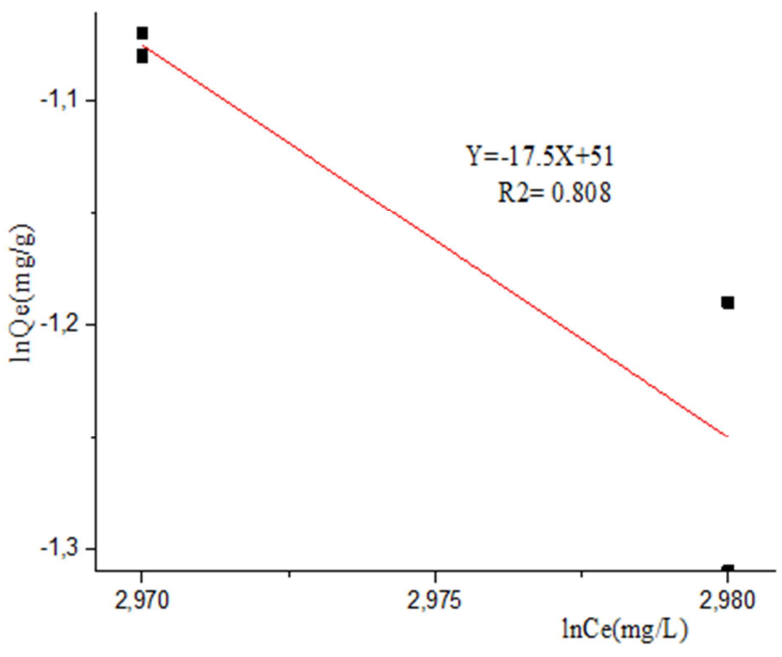

Figure 15. Linear plot of the Freundlich model.

The variation in the amount of triterpene extract adsorbed per gram of clay as a function of the concentration at equilibrium $(\mathrm{Ce})$ was determined and the results modeled. The adsorption parameters according to the Freundlich and Langmuir equations are summarized in Tables 4 below. As observed, the value of $\mathrm{R}^{2}$ obtained from the Langmuir isotherm equation (0.994) was higher than that from the Freundlich (0.808) isotherm equations. These results showed that the adsorption experiments data could be well described by the Langmuir model. The adsorption occurred on the homogeneous surface as a monolayer, and the maximum monolayer adsorption capacity $\left(\mathrm{q}_{\max }\right)$ was found to be 0.002 $\mathrm{mg} / \mathrm{g}$. Similar observation is made in the adsorption of methylene blue onto modified Tamazert kaolin [45]. The RL value was obtained within the range $0<\mathrm{RL}<1$, indicating that the adsorption of triterpene extract on the clay material is favorable.

\subsection{Kinetics Studies}

Adsorption kinetics is a very useful tool which gives a better comprehension of adsorption processes and mechanism. It also helps to examine the adsorbent's performance. The kinetics of triterpene extract adsorption on Boboyo clay was analyzed using first order, second order and intra-particle diffusion Lagergren models. The pseudo-firstorder kinetic model was suggested by Lagergren to describe the adsorption in solid/liquid systems based on adsorption capacity. The pseudo-second-order model can be applicable to the process involving chemisorption. The intra-particle diffusion model is another commonly used model, which is capable of identifying the reaction pathways and adsorption mechanisms and predicting the rate-limiting step [52]. The respective linearised equation of pseudo-first order, pseudosecond order models and intraparticle diffusion models are:

$$
\begin{gathered}
\operatorname{Ln}(\mathrm{qe}-\mathrm{qt})=-k_{1} t+\text { Lnqe } \\
\mathrm{t} / \mathrm{q}=1 / \mathrm{K}_{2} \mathrm{q}_{\mathrm{e}}{ }^{2}+\mathrm{t} / \mathrm{q}_{\mathrm{e}} \\
q_{t}=k \operatorname{kint} \sqrt{t}+C
\end{gathered}
$$

where $\mathrm{k}_{1}, \mathrm{k}_{2}$ and $\mathrm{k}_{\mathrm{int}}$ are the respective pseudo-first, pseudosecond order and intraparticle diffusion, kinetic constant, $\mathrm{q}_{\mathrm{e}}$ and $\mathrm{q}_{\mathrm{t}}$ are the respective amount of adsorbent at equilibrium and at time t, $\mathrm{C}$ is an indication of boundary layer effect of

\begin{tabular}{|c|c|c|c|c|c|c|c|c|}
\hline \multicolumn{2}{|c|}{ Pseudo first order } & \multicolumn{3}{|c|}{ Pseudo second order } & \multicolumn{4}{|c|}{ Intraparticle diffusion } \\
\hline $\mathrm{K}_{1}(\mathrm{~L} / \mathrm{min})$ & $Q_{1}(\mathrm{mg} / \mathrm{g})$ & $\mathbf{R}^{2}$ & $K_{2}$ (g/mg.min) & $Q_{2}(\mathrm{mg} / \mathrm{g})$ & $\mathbf{R}^{2}$ & $K_{\text {int }}\left(\mathrm{mg} / \mathrm{g} \cdot \mathrm{min}^{1 / 2}\right)$ & $\mathrm{C}_{1}\left(\mathrm{~m}^{2} / \mathrm{s}\right)$ & $\mathbf{R}^{2}$ \\
\hline 0.057 & 8.33 & 0.9207 & 3.988 & 0.23 & 0.9974 & 0.0092 & 0.1746 & 0.7726 \\
\hline
\end{tabular}
the adsorbent particles.

Table 5. Pseudo first order, pseudo second order and intraparticle diffusion parameters.

The kinetics of triterpene extract adsorption on Boboyo clay was analyzed using first order, second order and intraparticle diffusion Lagergren models in Table 5. The conformity between the experimental data and the predicted model is based on the values of the correlation coefficients $\left(\mathrm{R}^{2}\right)$, and the kinetics parameters with each regression coefficient are summarized in Table 5. The better fitting results along with the higher regression coefficients for the adsorbent can be gained when using the pseudo-second-order model $\left(\mathrm{R}^{2}=0.994\right)$ rather than pseudo-first-order model $\left(\mathrm{R}^{2}=0.920\right)$, indicating the chemisorption role is prevalent for of triterpene extracts removal in material. In addition, the calculated value of adsorption capacity, $\mathrm{q}_{\mathrm{e}}(0.23 \mathrm{mg} / \mathrm{g})$ is matched well with the experimental ones. These results implied that the adsorption was better described by the pseudo-second order kinetic, indicating that the adsorption mechanisms of triterpene extract depended on the adsorbate and adsorbent. The values of the calculated theoretical adsorbed quantities $(0.23 \mathrm{mg} / \mathrm{g})$ of the model of pseudosecond order are very close to adsorbed quantities obtained experimentally $(0.34 \mathrm{mg} / \mathrm{g})$. This model reflects the existence of strong interactions between the clay surface and the molecules of the adsorbates. 


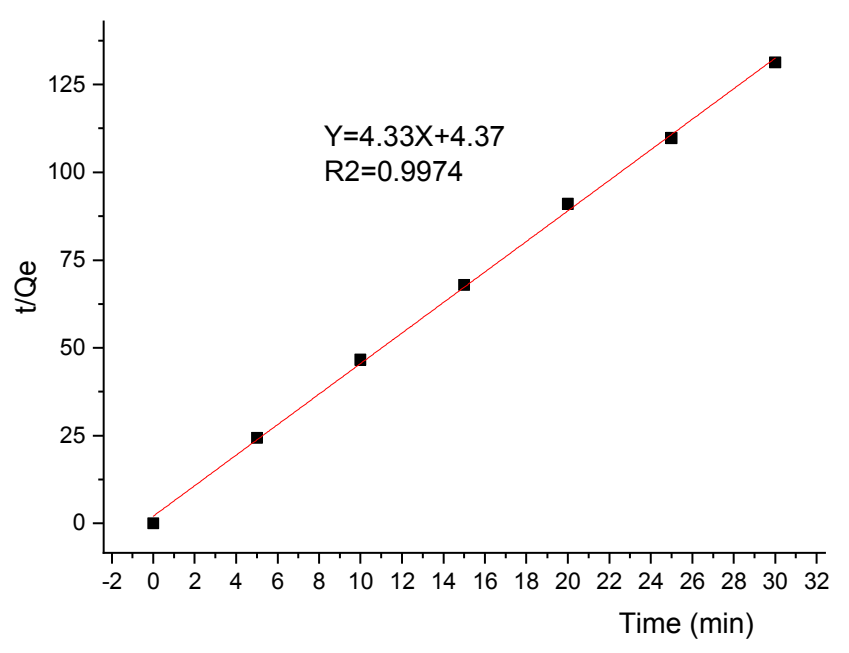

Figure 16. Linearized pseudo-first order plots.

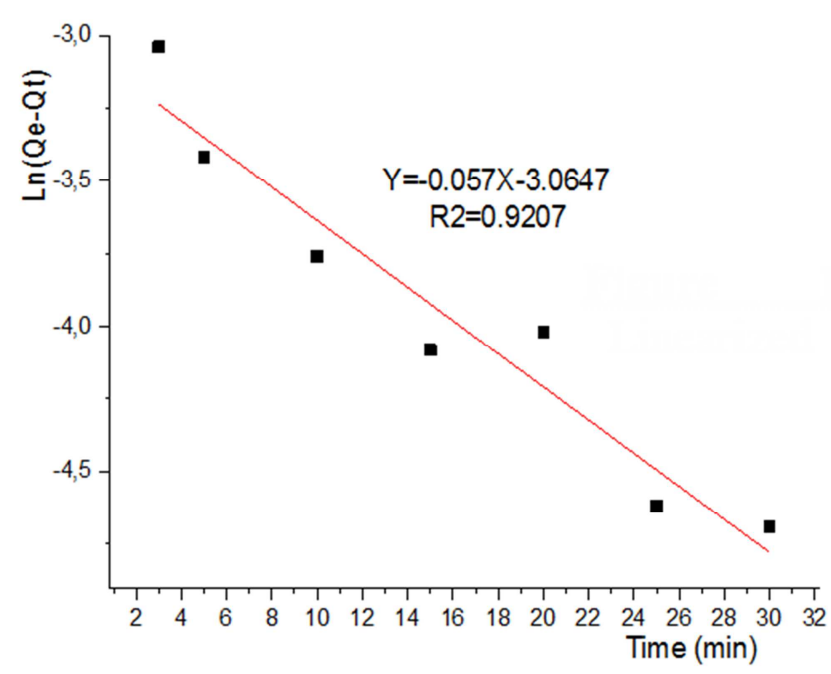

Figure 17. Linearized pseudo-second order plots.

\section{Conclusion}

The purpose of this present study is to enhance the extract from the leaves of Momordica charantia and Boboyo clay, using this natural clay as a support for organic compounds, in order to promote a powdery formulation of insecticide. The study of certain parameters which influence the adsorption in batch mode is done. The adsorption of triterpene extract is very rapid, and equilibrium is reached in less than 10 minutes The kinetic model of pseudo-second order is applicable to the adsorption of triterpene extract. The amounts adsorbed decrease with increasing mass of adsorbent and temperature. However, they increase with the increase in the initial concentration of triterpene extract. Adsorptions of triterpene extract onto the clays are more described by the Langmuir model with a maximum adsorption capacity of triterpene extract of $0.34 \mathrm{mg} / \mathrm{g}$, at $25^{\circ} \mathrm{C}$ and $100 \mathrm{mg} / \mathrm{L}$ initial concentration of triterpene extract. A pseudo second order kinetic model explained the rate of adsorption of triterpene extract on the adsorbents. The thermodynamic parameters $\Delta \mathrm{G}^{\circ}, \Delta \mathrm{H}^{\circ}$ and $\Delta \mathrm{S}^{\circ}$ indicated the spontaneity of the adsorption process even at lower temperature. The positive value of $\Delta \mathrm{H}^{\circ}$ showed the endothermic nature of the adsorption. The study of the adsorption of triterpene extract by Boboyo clay can be used for a powdery formulation of insecticide.

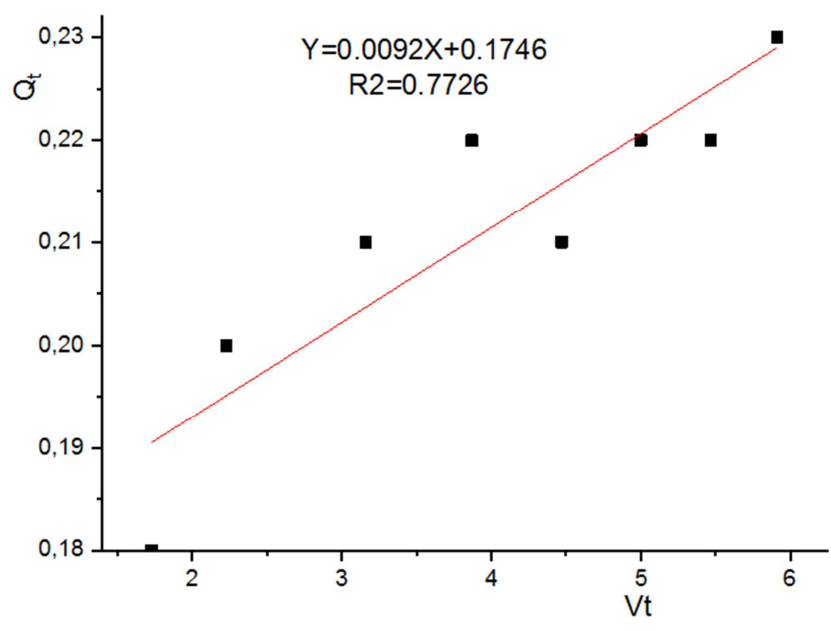

Figure 18. Linearized intraparticle diffusion plots.

\section{Funding}

This research did not receive any specific grant funding agencies in the public, commercial, or any-not-for-profit sectors.

\section{Data Availability}

The raw/processed data required to reproduce these findings cannot be shared at this time due legal or ethical reasons.

\section{Compliance with Ethical Standards}

Conflict of interest All authors declare that they have no competing interest.

\section{Acknowledgements}

The authors of this research are very thankful to Prof. Ketcha Mbadcam Joseph for his experimental contribution to this study.

\section{References}

[1] Vaghasiya J., Sheth N., Bhalodia Y. \& Manek R. Sitagliptin protects renal ischemia reperfusion induced renal damage in diabetes. Regul. Pept. 2011, 166, 48-54.

[2] Tulika T. Phytochemical screening of active metabolites present in Eichhornia crassipes (mart.) Solms and pistia stratiotes (1.): Role in ethanomedicine. Asian Journal of Pharmaceutical Education and Research. 2017, 6 (4): 40-56.

[3] Amas, Cluster, 1997. Food and Agricultural Research Council, Réduit, Mauritius. 
[4] Sana G, Mabrouk E, Stéphanie L, Samir B \& Mourad B. Adsorption of terpenic compounds onto organo-palygorskite. Environnemental Science and Pollution Research. 2018, 25 (19): 18251-18262.

[5] Dias M, Valério A, de Oliveira D, Ulson de Souza A A, \& de Souza S M G U. Adsorption of natural annatto dye by kaolin: kinetic and equilibrium. Environ. Technol. (United Kingdom) 2020, 41: 2648-2656.

[6] Anjamma M \& Lakshmi B N. GC-MS Analysis of Momordica charantia and Momordica dioica Fruit and Root Methanolic Extracts. International Journal of Pharmacognosy and Phytochemical Research. 2017.9 (6): 808-813.

[7] Satya V C \& Naresh, K. M. Momordica charantia: A natural medicinal plant. GSC Biological and Pharmaceutical Sciences, 2020, 12 (02): 129-135.

[8] Abdulrahim H A, Zubair M F, Ibrahim S O, Nafiu A B, Baba U A, Adebayo A A, Musa, D M, Omeiza N A \& Hamid A A. Physicochemical, Nutritional and Antioxidant Properties of Momordica charantia and Citrullus vulgaris seed oil extracts. Centrepoint Journal (Science Edition). 2017, 23 (2): 1-25.

[9] Adesina J M, Afolabi L A \& Ofuya T. Evaluation of insecticidal properties of Momordica charantia in reducing oviposition and seed damaged by Callosobruchus maculatus (Fab.) Walp. Journal of Agricultural Technology. 2012; 8 (1): 493-499.

[10] Obembe O M \& Ogungbite O C. Comparative Insecticidal Activities of some Botanical Powders and Pirimiphos-Methyl Against Callosobruchus maculatus Fab.[Coleoptera: Bruchidae] Infesting Cowpea Seeds. MOJ Biol. Med. 2017, 2 (4): 305-309.

[11] Shibu N J, Papiya M M \& Nagaraju, G. Momordica Charantia linn as a medicinal plant. World Journal of Pharmacy and Pharmaceutical Sciences. 2018, 7 (1): 440-459.

[12] Zijun G, Guocai W, Maoxin Z, Guangwen L, Qiang, L, Bing L. Evaluation of Cytotoxic Activity in vitro of Charantin A Extracted from Momordica charantia. Records of Natural Products. 2018, 12 (5): 416-425.

[13] William A S. G, Lídia A R V, Karine L S, Karla D N M, Raimundo B F, Patrícia G G N, Mírian P. M \& Mary A M B. Pharmacognostic Evaluation of Bitter Melon from Brazilian Northeast (Momordica charantia L.): Identification of Momordicin II. J Young Pharm. 2019, 11 (4), 366-370.

[14] Wen L, Zhaozhou L, Chengjie Y, Yubo W \& Yanjiang Q. Study on the chemical constituents of Momordica charantiaL. leaves and method for their quantitative determination. Biomedical Research. 2015, 26 (3): 415-419.

[15] Turek C \& Stintzing F C. Stability of essential oils: A review. Compr. Rev. Food Sci. Food Saf. 2013, 12: 40-53.

[16] Sékou M K, Vincent C, Schmit J P, Ramaswamy S \& Belanger, A., Effect of various essential oils on Callobruchus maculatus. Journal of Products Research. 2000, 36: 355-364.

[17] Nguemtchouin M M G, Ngassoum M B, Kamga R \& Cretin M. Characterization of acidic and alkali treated Kaolinite and montmorillonite clay from Adamawa and far-north region of Cameroon. Journal of Applied Chemical Science International. 2018, 9 (1): 26-38.
[18] Fabrice L2006. Development of formulations based on neem extracts (azadirachta indica. Juss) for the protection of potatoes (solanum tuberosum L.) Against Myzuspersicae, a colonizing aphid and vector of circulating and non-circulating viruses. Dissertation written for obtaining the degree of master of science.

[19] Popovich D G, Li L \& Zhang W. Bitter melon (Momordica charantia) triterpenoid extract reduces preadipocyte viability, lipid accumulation and adiponectin expression in 3T3-L1 cells. Food Chem. Toxicol. 2010; 48: 1619-1626.

[20] Suryawanshi P \& Vidyasagar G. M., Phytochemical screening for secondary metabolites of Opuntia dillenii Haw. Journal of Medicinal Plants Studies. 2016, 4 (5): 39-43.

[21] Alain P B B, N'guessan A F Y, Jean D \& Allico J D. Antioxidant activities of ten medicinal plants from the Ivorian pharmacopoeia. Science and nature. 2010, 8 (1): 1-11.

[22] Winda R, Jean-François F, Thamrin U \& Zephirin $M$. Adsorption Characteristics of Bixin on Acid- and AlkaliTreated Kaolinite in Aprotic Solvents. Bioinorganic Chemistry and Applications. 2018.

[23] Kavitha B \& Thambavani DDS. Physico-Chemical Characterization of Riverbed Sand from Mullai Periyar, Tamilnadu. IOSR J. Appl. Chem. 2014, 7, 54-56.

[24] Samaila M B \& Alayande K A. Comparative evaluation for the adsorption of toxic heavy metals on to millet, corn and rice husks as adsorbents. J Anal Pharm Res. 2019, 8 (3): 119-125.

[25] Nguetnkam J P, Kamga R, Villiéras F, Ekodeck G E, Razafitianamaharavo A J \& von, Y. Assessment of the surface areas of silica and clay in acid-leached clay materials using concepts of adsorption on heterogeneous surfaces. Journal of Colloid and Interface Science. 2005, 289: 104-115.

[26] Nguetnkam J P, Kamga R, Villiérasc F, Ekodeck G E \& Yvon, J. Assessing the bleaching capacity of some Cameroonian clays on vegetable oils. Applied Clay Science 2008, 39: 113121.

[27] Harouna M, Jean M, Djakba R, Bagamla W, Tcheka C, Mbadcam J \& Loura, B. Adsorption of Poly-phenolic Compounds of Optimized Extract of the Bark of Pittosporaceae by Pillared Clay in View of the Formulation of Powdered Insecticides. Am. Chem. Sci. J. 2016, 15: 1-10.

[28] Harouna M, Djakba R, Nguetnkam J P, Loura B B, Denisa I N \& Ketcha J. M. Adsorption of $\mathrm{Mn}^{2+}$ and $\mathrm{Zn}^{2+}$ in Aqueous Solution by Using Aluminum Pillared Clay from Boboyo (Far North Cameroon). American Chemical Science Journal. 2015, 5 (1): $94-104$

[29] Zaccheus S, Lamai W D, Ahm \& Ahmed M. Adsorption of Lead in Aqueous Solution using Montmorillonite-silica Nanocomposite. The Pharmaceutical and Chemical Journal. 2018, 4 (5): 27-34

[30] Iván F M, Gloria I G \& Nancy R. Characterization of Colombian Clay and Its Potential Use as Adsorbent. The Scientific World Journal. 2018, 11.

[31] Chikwe T N, Ekpo R E \& Okoye I. Competitive adsorption of organic solvents using Competitive modified and unmodified calcium bentonite clay mineral. Chemistry International. 2018, 4 (4), 230-239. 
[32] Lainé M, Balan E, Allard T, Paineau E, Jeunesse P, Mostafavi M, Robert J L \& Caër S L. Supporting information for Reaction mechanisms inswelling clays under ionizing radiation: influence of the water amount and of the nature of the clay. 2017,7 (1), 526-534.

[33] Qabaqous O, Tijani N, Bennani M N, \& Krouk, A. E. Preparation and characterization of supports plans from the (Rhassoul) Clay for mineral membranes. Mater. Environ. Sci. 2014, 5: 2244-2249.

[34] Maina E W, Wanyika H J, \& Gacanja A N. Instrumental Characterization of Montmorillonite Clay by FT-IR and XRD from J. K. U. A. T Farm, in the Republic of Kenya. Chemistry and Materials Research. 2015, 7 (10): 224-239.

[35] Supraja p, Basha T, Nagaraju CKiranmanyee \& P U R. Identification of an Alkaloid Momordicin From Fruits of Momordica Charantia L. Int. J. Sci. Eng. Res. 2015, 6, 168172.

[36] Sharma K, Morla S, Khaire K C, Thakur A, Moholkar V S, Kumar S \& Goyal A. Extraction, characterization of xylan from Azadirachta indica (neem) sawdust and production of antiproliferative xylooligosaccharides. Int. J. Biol. Macromol. 2020, 163: 1897-1907.

[37] Musa MSM, Sulaiman WRW, Majid ZA, Majid ZA, Idris AK \& Rajaei K. Henna extract as a potential sacrificial agent in reducing surfactant adsorption on kaolinite: The role of salinity. J. King Saud Univ. - Eng. Sci. 2019, 1-5.

[38] Nguemtchouin M M G, Ngassoum M B, Ngamo L S T, Mapongmetsem P M, Sieliechi, J, Malaisse F, Lognay G C, Haubruge E, \& Hance T. Adsorption of essential oil components of Xylopia aethiopica (Annonaceae) by kaolin from Wak, Adamawa province (Cameroon). Applied Clay Science. 2009, 44: 1-6.

[39] Ana C F, \& Joã, O P. Adsorption of Volatile Organic Compounds on Zeolite L. Journal of Chemical and Engineering Data. 2016, 61 (11): 3890-3896.

[40] Mohamed E, Kamal E, Doha B, Samira S \& Abdessalem T. Adsorption thermodynamics and isosteric heat of adsorption of Thymol onto sodic, pillared and organic bentonite. Mediterr. J. Chem. 2019, 8: 494-504.

[41] Mariana B, Enrique ET, \& Carlos R V. Coupling Solvent Extraction Units to Cyclic Adsorption Units. International Journal of Chemical Engineering. 2018, 1: 1-17.

[42] Jian W, Liang, Z \& Chao L. Quanxing Z. Adsorption Characteristics of Pentane, Hexane, and Heptane: Comparison of Hydrophobic Hypercrosslinked Polymeric Adsorbent with Activated Carbon. Journal of Chemical \& Engineering Data. 2012, 57 (12): 3426-3433.
[43] Nguemtchouin M G M, Ngassoum M B, Chalier P, Kamga R, Ngamo L S T \& Cretin, M. Ocimum gratissimum essential oil and modified montmorillonite clay, ameans of controlling insect pests in stored products. Journal of Stored Products Research. 2012, 52: 57-62.

[44] Ali B \& Kamel R. Improvement adsorption capacity of methylene blue onto modified Tamazert kaolin. Adsorption Science \& Technology. 2017, 35 (9-10): 753-773.

[45] El Gaidoumi A, Chaouni B A, Lahrichi A \& Kherbeche A. Adsorption du phénol en milieu aqueux par une pyrophyllite marocaine brute. J. Mater. Environ. Sci. 2014, 6 (8): $2247-$ 2259.

[46] Sakr F, Sennaoui A, Elouardi M, Tamimi M \& Assabbane A. étude de l'adsorption du Bleu de Méthylène sur un biomatériau à base de l'eucalyptus selon la taille des particules. J. Mater. Environ. Sci. 2016, 7: 4036-4048.

[47] Zohra D Y, Bouabdasselem H, \& Bettahar, N. Elimination of organic compounds by local clays. C. R. Chimie. 2006, 9: 1295-1300.

[48] Uday C G, Duyoy B, Biswarnjanmanna M M. Hydrous iron (III)-tin (IV) binary mixed oxide: Arsenic Adsorption Behavior from Aqueous Solution. Water Quality Research Journal of Canada. 2006, 41: 198-209.

[49] Aksas, H. Kinetic and thermodynamic study of the adsorption of heavy metals by the use of natural adsorbents. Doctoral thesis, M'Hamed Bougara-Boumerdes. 2013, University, Algeria. 199.

[50] Domga R, Harouna M, Tcheka C, Tchatchueng J B, Tsafam A, Dama N K \& Dikdim D. Batch Equilibrium, Kinetic and Thermodynamic Studies on Adsorption of Methylene Blue in Aqueous Solution onto Activated Carbon Prepared from Bos Indicus Gudali Bones. Chem. J. 2015, 1: 172-181.

[51] Yali S, Ebenezer A S, He W \& Hua, W. Adsorption of oxytetracycline on kaolinite. PLOSONE. 2019, 14 (11): $\mathrm{e} 0225335$.

[52] Jinjin L, Hao W, Ronghai Z, Honggang C, Gang X, Jingxian W, Hao F \& Ping, L. Economical Synthesis of High Surface Area $\gamma$-Al2O3 for the Adsorption of Organic Pollutant from Wastewater. American Journal of Chemical Engineering. 2020, 8 (4): 76-89.

[53] Adarsh S. Bhatt, Praful L. Sakaria, Manu Vasudevan, Radheshyam R. Pawar, N. Sudheesh, Hari C. Bajaj, Haresh M. Mody.,. Adsorption of an anionic dye from aqueous medium by organoclays: equilibrium modeling, kinetic and thermodynamic exploration. RSC Advances. 2012, 2: 86638671 . 